\title{
Studies on Corynebacterium pseudotuberculosis, Staphylococcus aureus and Staphylococcus aureus subsp. anaerobius isolated from sheep skin abscesses in Beni Suef Governorate.
}

\author{
Samia I. Afifi \\ Animal Health Research Institute
}

\begin{abstract}
Clinical examination of 380 rearing sheep revealed that 30 animal were suffering from skin abscesses with an incidence of $(\mathbf{7 . 8 9 \%})$. Bacteriological examination of 30 swabs from affected sheep revealed isolation of 30 isolates of $C$. pseudotuberculosis $(48.39 \%), 18$ isolates of $S$. aureus (29.03\%) and 14 isolates of $S$. aureus subsp. anaerobius (22.58). The isolated bacteria were identified morphologically and biochemically.The results of animal pathogenicity test showed that $C$. pseudotuberculosis isolates were $100 \%$ pathogenic to guinea pigs and $80 \%$ of $S$.aureus isolates were pathogenic to mice, while all isolates of $S$. aureus subsp. anaerobius were pathogenic to mice. The dead animals showed haemorrhage and symptoms of septicaemia, C. pseudotuberculosis, S.aureus and $S$. aureus subsp. anaerobius were reisolated from the dead animals. Antimicrobial sensitivity of $C$. pseudotuberculosis, $S$. aureus and $S$. aureus subsp. anaerobius isolates to some antimicrobial agents which usually used in farms showed that from $90 \%$ to $100 \%$ of $C$. pseudotuberculosis isolates were sensitive to erythromycin, amoxicillin, tetracycline, streptomycin, ampicillin and rifampicin while $S$. aureus isolates (from $55 \%$ to $66 \%$ ) were sensitive to rifampicin,tetracycline ,erythromycin and streptomycin, while $S$. aureus subsp. anaerobius isolates were moderately resistant to all used antimicrobial agents.
\end{abstract}

Corynebacterium pseudotuberculosis, the causative agent of Caseous lymphadenitis (CLA) which is a contagious bacterial disease that affects sheep and goats, continues to cause considerable economic losses in ovine and caprine herds worldwide (Dorella et al., 2009). The disease is characterized by abscess formation in the skin, internal and external lymph nodes, and internal organs, when the disease become endemic in a herd or flock it is difficult to eradicate by virtue of its poor response to therapeutics, its ability to persist in the environment, and the limitations in detecting subclinically affected animals. The disease causes significant economic impact on the small ruminant industry through decreased meat yield, damaged wool and leather, decreased reproductive efficiency, and mortality from the internal environment (Paton et al., 1988; Williamson, 2001; Baired and Fontain, 2007; O'Reilly et al., 2008).

The prevalence of CLA increases with age and the incidence increases only in young sheep after shearing. Sheep are sheared under unhygienic conditions, which may be a contributing factor in increasing both the prevalence and the incidence of CLA (Serikawa et al., 1993; Al-Rawashdeh and Qudah 2000; Paton et al., 2002). Bacteriological studies revealed that $C$. pseudotuberculosis was the pathogen which most frequently isolated, followed by Staphylococcus aureus (Tadayon et al., 1980; Unanian et al., 1985; Gezon et al., 1991; Moller, et al., 2000), and Staphylococcus aureus subsp. anaerobius, which is the etiological agent of abscess disease, a specific chronic condition of sheep and goats, which is characterized by formation of necrotic lesions that are located typically in superficial lymph nodes (Ben Sa ̃̃ et al., 2002; De la Fuente et al., 2010). This work was aimed to, threw light on $C$. Pseudotuberculosis, S. aureus and $S$. aureus subsp. anaerobius as a causative agents of skin abscess in sheep in Beni Suef Governorate, studying the pathogenicity of the isolated $C$. Pseudotuberculosis, S. aureus and $S$. aureus subsp. anaerobius to laboratory animals and the in vitro sensitivity of the isolated bacteria to some chemotherapeutic agents commonly used in farms.

\section{Materials and methods}

Bacteriological examination.

Samples. Out of 380 examined sheep for skin abscesses , 30 bactreological swabs were taken 
from sheep showing skin abscesses randomly in different localities in Beni Suef Governorate and collected in sterile containers and transported directly to the laboratory in ice box.

\section{Isolation and identification.}

Media. Tryptic soya agar, tryptic soya broth, mannitol salt agar, sheep blood agar, Muller Hinton agar and Muller Hinton broth.

Isolation and identification. All samples were cultured onto different media in duplicate plates and incubated under aerobic and anaerobic conditions (in anaerobic jar containing 5\% carbon dioxide) at $37^{\circ} \mathrm{C}$ for 24 to $48 \mathrm{~h}$, isolated colonies were purified and identified morphologically and biochemically according to (Cruick Shank, et al., 1975; Collee, et al., 1996)

Coagulase test. Human, sheep and rabbit plasma were used for coagulase test of Staphylococcus spp. according to (Cruick Shank et al., 1975; Collee et al., 1996)

Animal pathogenicity.

Pathogenicity test for $C$. pseudotuberculosis isolates. Twenty-two guinea pigs $(350-400 \mathrm{~g}$ weight) were used for testing the pathogenicity of 10 C. pseudotuberculosis isolates, two guinea pigs were used for each isolate and two controls. The animals were inoculated subcutaneously inside the lateral aspect of the hind limb with one dose of $1 \mathrm{ml}$ of $1 \times 10^{13}$ c.f.u / $\mathrm{ml}$ according to method described by (Barakat et al., 1973; Basma, et al., 2003), the control G.pigs were injected with sterile saline.

Pathogenicity test for $S$. aureus and $S$. aureus subsp. anaerobius isolates. Sixty-three Swiss albino mice $(15-20 \mathrm{~g})$ were divided into three groups, group one (30 mice) for testing $10 \mathrm{~S}$. aureus isolates, group two (30 mice) for testing $10 \mathrm{~S}$. aureus subsp. anaerobius isolates, (three mice for each isolate) and group three (3 mice) were kept as control. Group one and two were injected intraperitonialy with $0.5 \mathrm{ml}$ of $5 \times 10^{9}$ C.F.U/ $\mathrm{ml}$ of $S$. aureus and $S$. aureus subsp. anaerobius isolates respectively according to (Calvinho and Dodd, 1994; Nevine, 2001), the control mice were injected with sterile saline.

The mice and guinea pig were kept under observation for 2 weeks before they were inoculated and kept under observation for 7 days post-infection.
Antimicrobial sensitivity of C. pseudotuberculosis, S. aureus and $S$. aureus subsp. anaerobius isolates to some chemotherapeutic agents. The sensitivity of $C$. Pseudotuberculosis, S. aureus and S. aureus subsp. anaerobius isolates to some antibacterial agents which usually used in farms was examined by disc diffusion method using Muller Hinton agar and Muller Hinton broth media according to (Collee et al., 1996).

\section{Results}

Out of 380 examined sheep 30 animals were suffered from skin abscesses with an incidence of $(7.89 \%)$. Bacteriological examination of 30 swabs collected from affected sheep revealed isolation of 30 isolates of $C$. pseudotuberculosis 18 isolates of $S$. aureus and 14 isolates of $S$. aureus subsp. anaerobius as shown in Table (1) and Table (2).

Regarding to microscopic examination and biochemical reaction C. pseudotuberculosis were small pleomorhpic Gram-positive rods, aerobic and facultative anaerobic bacteria, colonies were white to cream in colour, regular, haemolytic, catalase and urease positive, fermented glucose and maltose. S.aureus and S. aureus subsp. anaerobius isolates were Gram-positive cocci oxidase negative coagulase positive, fermented mannitol, DNase and Lecithinase positive.

Animal pathogenicity. All injected guinea pigs dead within few days post injection with $C$. Pseudotuberculosis isolates and the post-mortem examination showed haemorrhage at the site of injection and haemorrhagic necrosis .On the other hand $80 \%$ of mice injected with $S$. aureus isolates were dead and showed symptoms of septicaemia, while all mice injected with $S$. aureus subsp. anaerobius were dead.

Table (1): Incidence of some bacterial isolates recovered from skin abscesses in sheep.

\begin{tabular}{lll}
\hline Bacterial isolates & No & $\%$ \\
\hline C. pseudotuberculosis & 30 & 48.39 \\
S. aureus & 18 & 29.03 \\
S. aureus subsp. anaerobius & 14 & 22.58 \\
Total & 62 & 100.00 \\
\hline
\end{tabular}

$\%$ was calculated according to the total No of isolates 
Table (2): Incidence of mixed bacterial infection in swabs from skin abscesses in sheep.

\begin{tabular}{lcc}
\hline Bacterial isolates & No & \% \\
\hline C. pseudotuberculosis + S. Aureus & 16 & 53.33 \\
C. pseudotuberculosis + S. aureus subsp. Anaerobius & 12 & 40 \\
C.pseudotuberculosis + S. aureus + S.aureus subsp. Anaerobius & 2 & 6.67 \\
Total & 30 & 100 \\
\hline
\end{tabular}

Table (3): Coagulase activities of $S$. aureus and $S$. aureus subsp. anaerobius isolated from skin abscesses in sheep.

\begin{tabular}{lccccccc}
\hline \multirow{2}{*}{ Species } & \multirow{2}{*}{ No } & \multicolumn{2}{c}{ Rabbit plasma } & \multicolumn{2}{c}{ Sheep plasma } & \multicolumn{2}{c}{ Human plasma } \\
\cline { 2 - 8 } & & No & \% & No & \% & No & \% \\
S. aureus & 18 & 18 & 100 & 15 & 83.33 & 16 & 88.89 \\
S. aureus subsp. anaerobius & 14 & 14 & 100 & 13 & 92.86 & 14 & 100 \\
\hline
\end{tabular}

Table (4): Pathogenicity test of some isolates of C. pseudotuberculosis, S.aureus and S. aureus subsp. anaerobius recovered from skin abscesses in sheep to the susceptible laboratory animals.

\begin{tabular}{|c|c|c|c|c|c|c|c|c|c|c|c|}
\hline \multirow[t]{2}{*}{ Bacterial species } & \multirow{2}{*}{$\begin{array}{c}\text { No. of } \\
\text { tested } \\
\text { isolates }\end{array}$} & \multirow{2}{*}{$\begin{array}{c}\text { No. of } \\
\text { infected } \\
\text { animals }\end{array}$} & \multicolumn{7}{|c|}{ No. of dead animal per day } & \multicolumn{2}{|c|}{$\begin{array}{l}\text { Total dead } \\
\text { animal }\end{array}$} \\
\hline & & & $1^{\text {st }}$ & $2^{\text {nd }}$ & $3^{\text {rd }}$ & $4^{\text {th }}$ & $5^{\text {th }}$ & $6^{\text {th }}$ & $7^{\text {th }}$ & No. & $\%$ \\
\hline $\begin{array}{l}\text { C. Pseudotuberculosis } \\
\text { (guinea pig ) }\end{array}$ & 10 & 20 & - & 12 & 5 & 1 & 2 & 0 & 0 & 20 & 100 \\
\hline S. aureus (mice) & 10 & 30 & - & 5 & 8 & 8 & 3 & 0 & 0 & 24 & 80 \\
\hline S.aureus-subsp. anaerobius & 10 & 30 & - & 8 & 10 & 12 & 0 & 0 & 0 & 30 & 100 \\
\hline
\end{tabular}

Table (5): Antimicrobial sensitivity of C. pseudotuberculosis, S.aureus S. aureus subsp. anaerobius isolated from skin abscesses in sheep to different chemotherapeutic agents.

\begin{tabular}{|c|c|c|c|c|c|c|c|c|c|}
\hline \multirow{3}{*}{$\begin{array}{l}\text { Chemotherapeutic } \\
\text { agents }\end{array}$} & \multicolumn{3}{|c|}{$\begin{array}{l}\text { C. Pseudotuberculosis } \\
\text { isolates (30) }\end{array}$} & \multicolumn{3}{|c|}{ S. aureus isolates (18) } & \multicolumn{3}{|c|}{$\begin{array}{l}\text { S. aureus subsp. } \\
\text { anaerobius (14) }\end{array}$} \\
\hline & \multirow{2}{*}{$\mathbf{R}$} & \multicolumn{2}{|c|}{$\mathbf{S}$} & \multirow{2}{*}{$\mathbf{R}$} & \multicolumn{2}{|c|}{$\mathbf{S}$} & \multirow{2}{*}{$\mathbf{R}$} & \multicolumn{2}{|c|}{$S$} \\
\hline & & No & $\%$ & & No & $\%$ & & No & $\%$ \\
\hline Erythromycin $(15 \mu \mathrm{g})$ & 0 & 30 & 100 & 8 & 10 & 55.56 & 6 & 8 & 57.14 \\
\hline Amoxicllin $(30 \mu \mathrm{g})$ & 2 & 28 & 93.33 & 10 & 8 & 44.44 & 8 & 6 & 42.86 \\
\hline Ampicillin $(30 \mu \mathrm{g})$ & 2 & 28 & 93.33 & 10 & 8 & 44.44 & 9 & 5 & 35.71 \\
\hline Streptomycin $(30 \mu \mathrm{g})$ & 3 & 27 & 90 & 8 & 10 & 55.56 & 7 & 7 & 50 \\
\hline Penicillin (10 IU) & 20 & 10 & 33.33 & 18 & 0 & 0 & 14 & 0 & 0 \\
\hline Rifampicin $(30 \mu \mathrm{g})$ & 3 & 27 & 90 & 9 & 9 & 50 & 5 & 9 & 64.29 \\
\hline Tetracycline $(30 \mu \mathrm{g})$ & 2 & 28 & 93.33 & 6 & 12 & 66.67 & 5 & 9 & 64.29 \\
\hline
\end{tabular}

$\mathrm{S}=$ Sensitive

\section{Discussion}

Caseous lymphadenitis (CLA) of sheep, caused by $C$. pseudotuberculosis, has been a significant disease in the majority of sheeprearing regions for over a century. Because of the chronic and often sub-clinical nature of the infection, it has proved difficult to control and prevalence in many parts of the world, which in turn leads to significant economic losses for farmers (Baired and Fontaine, 2007). Caseous lymphadenitis causes an annual loss of about $\$ 17$ million in wool production to the Australian wool industry (Paton et al., 1994). S. aureus and $S$. aureus subsp. anaerobius were the microorganisms isolated from the affected animals beside C. pseudotuberculosis, (Tadayon, et al., 1980; Ben SaÃ et al., 2002; De la Fuente et al., 2010). In this work out of 380 examined sheep 30 animals were suffering from skin abscesses with an incidence of $(7.89 \%)$. Paton et al.,( 2003) stated that, the average prevalence of CLA in adult sheep flocks was $26 \%$ and varied from 20\% in Western Australia to $29 \%$ in New South Wales, Ellis et al., (1990) stated that the overall prevalence of $C$. pseudotuberculosis-positive CL lesions in 104 sheep was 31.7\% and Amany and Halla, (2008) recorded high percentage from slaughtered animals, the difference in results may be attributed to limitations in detecting subclinically affected animals and the methods used for examination of living animals. Bacteriological examination of 30 swabs from affected sheep revealed isolation of 30 isolates of $C$. 
pseudotuberculosis (48.39\%) and 18(29,03\%) isolates of $S$. aureus as shown in table (1) and (2), Skalka et al.,( 1998) and Komala et al., (2008)isolated C. pseudotuberculosis from affected sheep at different rates and Amany and Halla (2008) isolated C. pseudotuberculosis and $S$. aureus from lymph nodes of slaughtered goat at percentage of 9.78 and $16.30 \%$ respectively, the variation in rate of isolation was due to difference in localities and history of the disease. S. aureus subsp. anaerobius was isolated from 14 sawbs (22.58\%) Alhendi et al., (1993) recorded an outbreak of abscess disease in goats in Saudi Arabia caused by $S$. aureus subsp. anaerobius infection, and BenSaA et al., (2002) cleared that $S$. aureus subsp anaerobius was particularly isolated from abscesses in sheep aged between 3 months and 2 years old. The results of microscopic examination and biochemical reaction of C. Pseudotuberculosis, $S$. aureus and $S$. aureus subsp. anaerobius agreed with the finding mentioned by Kathleen et al., (2000), Nevine (2001), and Rosario et al., (2000) respectivly.

Regarding to virulence factor (coagulase activities) table (3) of $S$. aureus and $S$. aureus subsp. anaerobius, $S$. aureus subsp. anaerobius isolates, showing relatively higher coagulase activities on the all used types of plasma than S.aureus isolates, this achieved the results explained by (Ben $\mathrm{SaA}$ et al., 2002, and De la Fuente et al., 2010). Table (4) cleared that the tested isolates of C. Pseudotuberculosis were $100 \%$ pathogenic to guinea pigs the results agreed with Collee et al., (1996) and resemble the results recorded by Basma et al., (2003), post-mortem examination showed haemorrhage at the site of injection and haemorrhagic necrosis may be due to phospholipase D exototoxins produced by the injected C. Pseudotuberculosis isolates which explained by Zaki (2004) .In case of $S$. aureus isolates $80 \%$ were able to killed mice in the first few days, the dead animals showed symptoms of septicaemia similar results were recorded by Nevine (2001) while S. aureus subsp. anaerobius isolates were $100 \%$ pathogenic to infected mice, this results agreed with Rosario et al., (2000). Table (5) clearing the antimicrobial sensitivity of $C$. pseudotuberculosis, S.aureus and S. aureus subsp. anaerobius isolated from skin abscess in sheep to different chemotherapeutic agents, $C$. pseudotuberculosis isolates were sensitive to erythromycin, amoxicillin, tetracycline, streptomycin, ampicillin and rifampicin,
Kathleen et al.,(2000) recorded similar results on the other hand most of S.aureus and S. aureus subsp. anaerobius isolates were resistant to all antimicrobial agents used variable rate of resistance were recorded by Amany and Halla, (2008) and Kumar (2008) . Variation in susceptibility of the isolates is return to the genetic contents of the isolates and the uses of the different chemotherapeutic agents by farmers. In conclusion the examination of 380 rearing sheep revealed that 30 animal were suffering from skin abscess with an incidence of (7.89\%). Bacteriological examination of 30 swabs from affected sheep revealed isolation of 30 isolates of C. pseudotuberculosis (48.39\%), 18 isolates of $S$. aureus $(29.03 \%)$ and 14 isolates of S. aureus subsp. anaerobius (22.58). C. Pseudotuberculosis isolates were highly pathogenic to laboratory animals and sensitive to chemotherapeutic agents used while $S$. aureus and $S$. aureus subsp. anaerobius isolates were pathogenic to laboratory animals and moderately resistant to chemotherapeutic agents used.

\section{References}

Alhendi, A. B.; Al-Sanhousi, S. M.; Al-Ghasnawi, Y. A. and Madawi, M.(1993): An outbreak of abscess disease in goats in Saudi Arabia.Zent. Vet. A., 40(9-10):646-651.

Al-Rawashdeh, O. F. and Al-Qudah K. M. (2000): Effect of shearing on the incidence of caseous lymphadenitis in Awassi sheep in Jordan. J. Vet. Med. B. Infect. Dis. Vet. Pub. Hlth., 47(4):287-293.

Amany, H. El. G.; and Halla, S. I.; (2008): Investigations on bacteria present in lymph nodes of slaughtered goat and studing the slime production by S. aureus. Egypt. Vet.Med. Assoc., 69 (1) 231-243.

Baird G. J. and Fontainem, M. C. (2007): Corynebacterium pseudotuberculosis and its role in ovine caseous lymphadenitis. J. Comp. Pathol., 137(4):179-210. Barakat, A. A; Saber, M. S. and Awad, H. H. (1973): The average standared of C. Pseudotuberculosis dose to produce either morbidity or lethality in G.pig . $11^{\text {th }}$ Ann. Arab. Vet Med. Congress. Cairo, Egypt.

Basma, Sh., Afaf, A. Y., and Eman. M. N., (2003): Studies on C. pseudotuberculosis in sheep affection Egypt. Vet. Med. Assoc. 63(2): 147-155.

Ben Sad M. S.; Ben Maitigue, H.; Benzarti, M.; Messadi L.; Rejeb, A.; Amara, A. (2002): Epidemiological and clinical studies of ovine caseous lymphadenitis. Arch. Inst. Pasteur Tunis. 79(1-4):51-57.

Calvinho, L. F. And Dodd, K. (1994): Virulance for mice of $\mathrm{S}$. aureus strains from bovine mastitis related to colonial morphology and serological types in serum soft agar. J. Vet. Med. Ser. B., 41 (5) :328-335.

Collee, J. G.; Fraser, A. Ca., Marmion, B. P. and Simmons, A. (1996): Practical medical microbiology. $14^{\text {th }}$ Ed. Charchill Livingstone. New-York, Edinbourgh London, Madrid Melbourne, Sanfrancisco and Tokyo.

Cruick Shank, R. ; Duguid, J. P. ; Marion, B. P. and Swain, R.H.A (1975): Medical Microbiology. $12^{\text {th }}$ ed., Vol II. Churchill Livingstone, Edinburgh, London and New - 
York.

De la Fuente R.; DÃez R.M; DomÃnguez-B. G.;Orden J.A; MartÃnez-P. S. (2010). Restoring catalase activity in Staphylococcus aureus subsp. anaerobius leads to loss of pathogenicity for lambs. Vet Res., 41(4):7-8.

Dorella, F. A.; Pacheco, L. G.; Seyffert, N.; Portela, R. W.; Meyer R.; Miyoshi A. and Azevedo V. (2009): Antigens of Corynebacterium pseudotuberculosis and prospects for vaccine development. Expert. Rev. Vac. 8(2): 205-213.

Ellis, J. A.; Hawk, D.A.; Holler, L.D.; Mills, K. W. and Pratt D. L. (1990): Differential antibody responses to Corynebacterium pseudotuberculosis in sheep with naturally acquired caseous lymphadenitis. J. Am. Vet. Med. Assoc., 196 (10):1609-1613.

Gezon H. M.; Bither, H. D.; Hanson L. A. and Thompson, J. K. (1991): Epizootic of external and internal abscesses in a large goat herd over a 16-year period. J. Am. Vet. Med. Assoc., 198 (2):257-263.

Kathleen, M. C.; Malcolm, M.; Graham, B. and William, D. (2000): Characterization of United Kingdom Isolates of Corynebacterium pseudotuberculosis using pulsed-field gel electrophoresis J. Clin. Microbiol., 38: 72633-2637.

Komala, T. S.; Ramlan, M.; Yeoh, N. N.; Surayani, A. R.; Sharifah, H. S. M. (2008): A survey of caseous lymphadenitis in small ruminant farms from two districts in Perak, Malaysia -- Kinta and Hilir Perak. Trop. Biomed. 25(3):196-201.

Kumar, J. K. (2008): Lysostaphin: an antistaphylococcal agent. Appl. Microbiol. Biot., 80(4):555-61.

Moller K.; Agerholm J. S.; Ahrens P.; Jensen N. E. and Nielsen, T. K. (2000): Abscess disease, caseous lymphadenitis, and pulmonary adenomatosis in imported sheep. J. Vet. Med. B. Infect. Dis. Vet. Pub. Hlth., 47(1):5562

Nevine, M. S. (2001): Virulence factors of Staphylococci isolated from mastitic ewes. Egypt. Vet. Med. Assoc..61 (6B):229- 238 .

O'Reilly, K. M.; Green, L. E.; Malone, F. E. and Medley, G. F. (2008): Parameter estimation and simulations of a mathematical model of Corynebacterium pseudotuberculosis transmission in sheep. Prev. Vet. Med. 83(3-4):242-259.
Paton, M. W.; Buller, N. B.; Rose, I. R. and Ellis, T.M. (2002): Effect of the interval between shearing and dipping on the spread of Corynebacterium pseudotuberculosis infection in sheep. Aust. Vet. J., 80(8):494-496.

Paton, M.W.; Rose, I. R.; Hart, R. A.; Sutherland, S. S.; Mercy, A. R.; Ellis, T. M. and Dhaliwal, J. A. (1994): New infection with Corynebacterium pseudotuberculosis reduces wool production. Aust. Vet.. J., 71(2):47-49.

Paton, M. W.; Mercy, A. R.; Wilkinson, F.C.; Gardner J. J.; Sutherland, S. S. and Ellis T.M. (1988): The effects of caseous lymphadenitis on wool production and bodyweight in young sheep. Aust. Vet. J., 65(4):117-119. Paton, M. W.; Walker, S. B.; Rose, I. R. and Watt, G.F. (2003): Prevalence of caseous lymphadenitis and usage of caseous lymphadenitis vaccines in sheep flocks. Aust. Vet. J., 81(1-2):91-95.

Rosario, S.; Marín, I.; Jose, A.; Ruiz, S. Q.; Jose, A. O.; Dolores, C.; Rosa, M. D.; Souad, S.; Ricardo, A. and Ricardo, de la F. (2000): Catalase deficiency in Staphylococcus aureus subsp. anaerobius is associated with natural loss-of-function mutations within the structural gene J. Microbiol., 146: 465-475.

Serikawa, S.; Ito S.; Hatta, T.; Kusakari, N.; Senna, K.; Sawara, S.; Hiramune, T.; Kikuchi, N. and Yanagawa, R. (1993): Seroepidemiological evidence that shearing wounds are mainly responsible for Corynebacterium pseudotuberculosis infection in sheep. J. Vet. Med. Sci. 55(4):691-692.

Skalka, B.; Literák, I.; Michalík, I. and Skrivánek, M. (1998): Corynebacterium pseudotuberculosis infection in goats in the Czech Republic. Zent. Vet. B., 45(1):31-35.

Tadayon, R. A.; Cheema, A. H. and Muhammed, S.I. (1980): Microorganisms associated with abscesses of sheep and goats in the south of Iran. Am. J. Vet. Res., 41(5):798802.

Unanian, M. M.; Feliciano, Silva A. E. and Pant, K. P. (1985): Abscesses and caseous lymphadenitis in goats in tropical semi-arid north-east Brazil. Trop Anim Health Prod., 17(1):57-62.

Williamson, L. H. (2001): Caseous lymphadenitis in small ruminants. Vet. Clin. North Am. Food Anim. Pract. 17(2):359-371.

Zaki, E. R. (2004): Assessment of the role played by C. Pseudotuberculosis exotoxin in inducing Oedematous skin disease in buffaloes. Egypt. Vet. Med. Assoc. 64 (6): 171181.

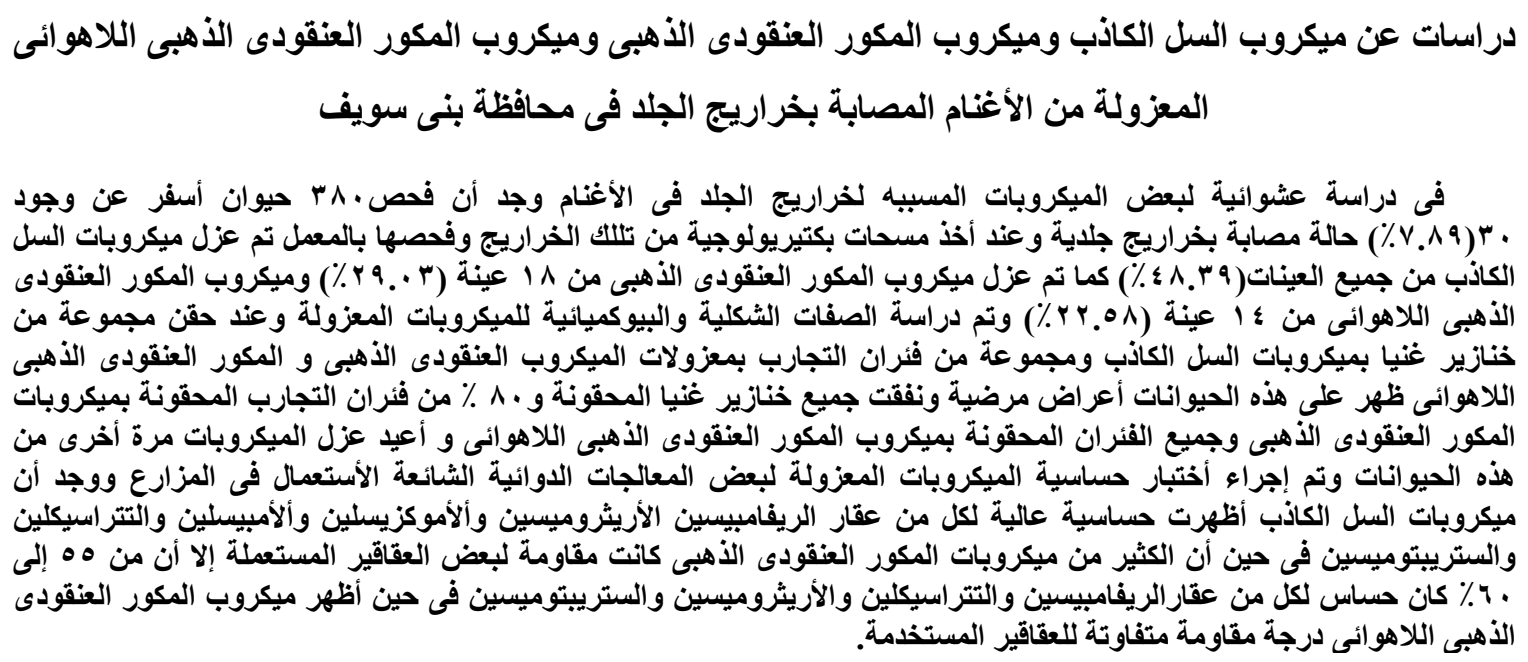

